\title{
Profile of drug users in Karachi city, Pakistan
}

H. Ali, R. Bushra and N. Aslam ${ }^{7}$

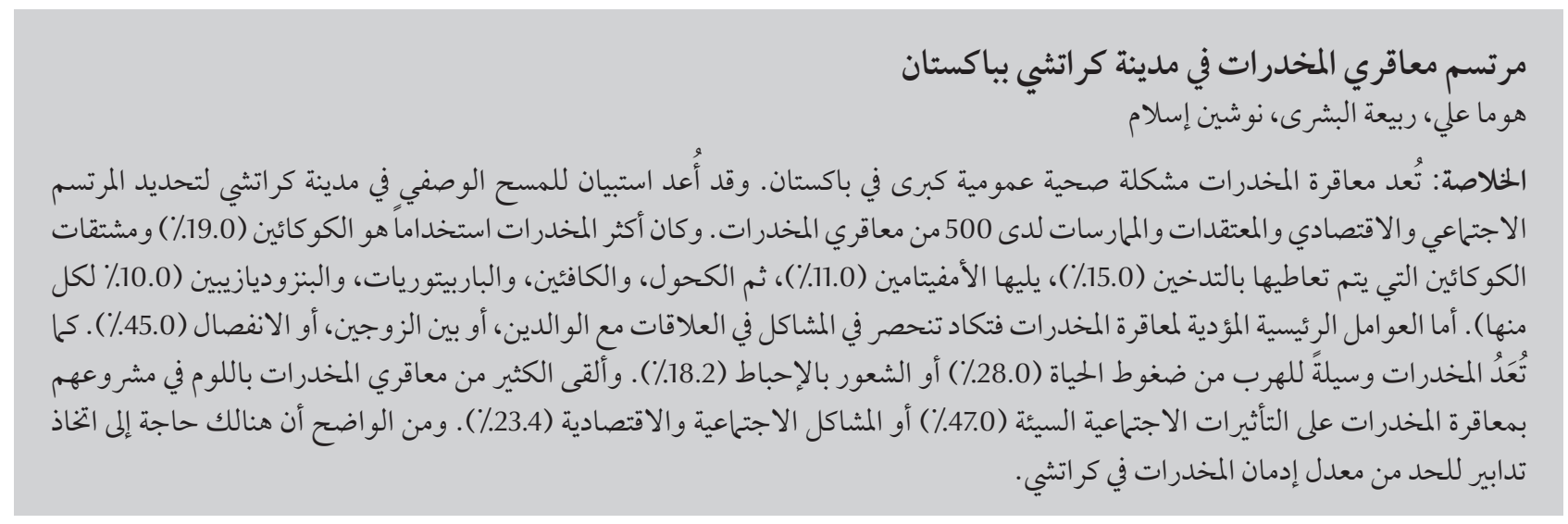

ABSTRACT Drug use has been identified as a major public health issue in Pakistan. A descriptive questionnaire survey in Karachi city was made to identify the socioeconomic profile and beliefs and practices of 500 drug users. The most commonly used drugs were cocaine (19.0\%) and crack-cocaine $(15.0 \%)$, followed by amphetamines (11.0\%), alcohol, caffeine, barbiturates and benzodiazepines (10.0\% each). Key psychological factors leading to drug use were problems with parental or marital relations or break-up of a relationship (45.0\%). Drugs were seen as an escape from stressful life events (28.0\%) or feelings of failure (18.2\%). Many drug users blamed the origins of their drug use on bad social influences (47.0\%) or socioeconomic problems (23.4\%). Preventive measures are needed to decrease the rate of drug addiction in Karachi.

\section{Profil des utilisateurs de drogues dans la ville de Karachi (Pakistan)}

RÉSUMÉ L'usage de drogues a été identifié comme un problème de santé publique majeur au Pakistan. Une enquête descriptive par questionnaire dans la ville de Karachi a été élaborée pour identifier le profil socioéconomique de 500 utilisateurs de drogues, leurs croyances et leurs pratiques. Les drogues les plus fréquemment utilisées étaient la cocaïne (19,0 \%) et le crack (15,0 \%), suivies par les amphétamines (11,0 \%), l'alcool, la caféine, les barbituriques et les benzodiazépines (10,0\% respectivement). Les facteurs psychologiques déclenchants conduisant à l'utilisation de drogues étaient les problèmes relationnels avec des parents ou avec des conjoints ou une rupture relationnelle $(45,0 \%)$. Les drogues étaient perçues comme une échappatoire aux événements stressants de la vie (28,0 \%) ou aux sentiments d'échec (18,2 \%). De nombreux utilisateurs de drogues expliquaient que les mauvaises fréquentations $(47,0 \%)$ ou les problèmes socio-économiques $(23,4 \%)$ étaient à l'origine de leur utilisation de drogues. Des mesures préventives sont nécessaires pour réduire le taux de toxicomanie à Karachi. 


\section{Introduction}

Drug dependence is defined as "....a state arising from repeated, periodic or continuous administration of a drug that results in harm to the individual and sometimes to society" [1]. There is a large and growing body of research on the causes, risk factors and correlates of substance use [2-7]. Generally, addictive drugs can act as positive reinforcers (producing euphoria) or as negative reinforcers (alleviating symptoms of withdrawal or dysphoria) [6,7]. The drug abuser may expect or perceive the benefits of drug use as the attainment of pleasurable feelings (relaxation), increased social interactions (reduced inhibition), alteration of their psychological condition to a more desirable state (escapism), physical changes (anabolic steroids) or avoidance of withdrawal symptoms in someone who is dependent on drugs [8].

According to the World drug report 2000, from the United Nations Drug Control Programme, Pakistan is one of the countries hardest hit by the narcotics industry [9]. According to a survey in 2005 there are about 3.5 million drug abusers, and the numbers are growing at an annual rate of $7 \%$ [10]. An examination of the social and demographic correlates of drug users in Karachi revealed that $71.5 \%$ were aged less than 35 years, with the highest proportion in the $20-30$ years age group [10]. Almost $50 \%$ of drug users were illiterate, yet, surprisingly, a similar percentage was employed. Among occupational categories, the frequency of drug abuse was highest among those in skilled and unskilled labour categories (50.8\%), followed by sales (16.8\%), agriculture (7.4\%) and students (7.4\%) [10].

The present study aimed to add to the body of knowledge about drug use in Pakistan by describing the socioeconomic profile and beliefs and practices of a sample of drug users in the city of Karachi, Pakistan.

\section{Methods}

This was a descriptive questionnaire study of drug users in Karachi city, Pakistan. Karachi is one of the world's largest cities in terms of population (around 18 million), with a mix of ethnic groups.

\section{Sample}

The sample was a convenience sample of 500 drug users located from different areas of Karachi and including people from different age groups, social backgrounds and employment status. A group of volunteer students from Ziauddin University were trained in how to conduct interviews and fill the questionnaire. The field workers visited different areas of the city which had a reputation of being places used by drug addicts and identified suitable people to interview. Some drug users were identified from personal contacts through the university.

All individuals participating in the study were initially approached by the field workers and informed about the objectives of the study and were given an explanation about the questionnaire, that participation was entirely on a voluntary basis and that responses were anonymous. The study was approved by the ethical committee of Ziauddin University.

The drug users were interviewed by a researcher using a structured questionnaire, which was also translated into Urdu language to assist those who wished to complete it themselves. The specially-designed questionnaire comprised 25 close-ended plus 5 openended questions. The demographic data of participants was limited to age, sex and occupation. The survey form was designed to obtain information about the respondents' drug use practices (types of drugs used, sources of drugs and frequency and routes of use); attitudes to their drug use (motivation for drug use in terms of mood before and after taking drugs, and its effect on social relationships and their role in society); and beliefs (about the causes of their drug dependency and parental/ family response to drug use).

The data were analysed and presented as simple frequencies and percentages.

\section{Results}

\section{Demographic data}

Out of the 500 participants, 389 (77.8\%) were males and 111 (22.2\%) were females. A majority of respondents (59.4\%) were aged $15-30$ years (Table 1). The occupations of the drug users were: employer (22\%), student (15\%), beggar (29.6\%), general duty servant (25\%) and other (9.4\%).

\begin{tabular}{lcccccc}
\hline \multicolumn{2}{l}{ Table 1 Age and sex distribution of the sample of drug users } & \multicolumn{2}{c}{} \\
\hline Age group (years) & \multicolumn{2}{c}{ Total $(\boldsymbol{n}=\mathbf{5 0 0})$} & \multicolumn{2}{c}{ Males $(\boldsymbol{n}=\mathbf{3 8 9})$} & \multicolumn{2}{c}{ Females $(\boldsymbol{n}=\mathbf{1 1 1})$} \\
& No & $\%$ & No. & No & $\%$ & No. \\
$15-20$ & 112 & 22.4 & 97 & 86.6 & 15 & 13.4 \\
$21-30$ & 185 & 37.0 & 139 & 75.0 & 46 & 24.8 \\
$31-40$ & 145 & 29.0 & 106 & 73.1 & 39 & 26.8 \\
$41-50$ & 58 & 11.6 & 47 & 81.0 & 11 & 18.9 \\
\hline
\end{tabular}




\section{Pattern of drug use}

The most commonly used drugs were cocaine $(19.0 \%)$ and crack-cocaine (15.0\%), followed by amphetamines (11.0\%), alcohol, caffeine, barbiturates and benzodiazepines (10.0\% each). Most of the individuals had poly-drug addiction.

Nasal inhalation was reported to be the most frequent mode of administration of drugs (31.6\%), followed by smoking $(28.0 \%)$, oral (19.6\%) and parenteral routes (8.0\%). About $12.8 \%$ used a combination of oral and parenteral modes (Table 2).

Most drug users (67.0\%) obtained their drugs from an unknown person, while $23.0 \%$ obtained supplies from a friend and $10.0 \%$ from a pharmacy.

\section{Motivation for taking drugs}

Before taking drugs many of the respondents reported physical symptoms such as feelings of "creeping" / dizziness/body aches (24.2\%), sleep problems (18.6\%) and vertigo/headaches (17.8\%). Other respondents had mood problems, such as anxiety/ anger (23.4\%) and depression (16.0\%) (Table 3). After taking drugs they reported feelings of calm and peacefulness $(22.0 \%)$, that all their problems were solved (19.4\%) or a general elevation of mood (12.8\%).

Table 2 Types of substances used, frequency of drug use and source of money of the sample of drug users $(n=500)$

\begin{tabular}{|c|c|c|}
\hline Variable & $\begin{array}{l}\text { No. of } \\
\text { respondents }\end{array}$ & $\%$ \\
\hline \multicolumn{3}{|l|}{ Type of substance used } \\
\hline Cocaine & 95 & 19.0 \\
\hline Crack-cocaine & 75 & 15.0 \\
\hline Amphetamines & 55 & 11.0 \\
\hline Alcohol & 50 & 10.0 \\
\hline Barbiturates & 50 & 10.0 \\
\hline Benzodiazepines & 50 & 10.0 \\
\hline Caffeine & 50 & 10.0 \\
\hline Ecstasy & 25 & 5.0 \\
\hline Cannabis & 25 & 5.0 \\
\hline Morphine and its analogs & 25 & 5.0 \\
\hline \multicolumn{3}{|c|}{ Route of administration of drugs } \\
\hline Nasal inhalation & 158 & 31.6 \\
\hline Smoking & 140 & 28.0 \\
\hline Oral & 98 & 19.6 \\
\hline Parenteral & 40 & 8.0 \\
\hline Oral + parenteral & 64 & 12.8 \\
\hline \multicolumn{3}{|l|}{ Frequency of drug use } \\
\hline Once a day & 91 & 18.2 \\
\hline Twice a day & 111 & 22.2 \\
\hline Alternate days & 81 & 16.2 \\
\hline When needed & 217 & 43.4 \\
\hline \multicolumn{3}{|c|}{ Source of money for buying drugs } \\
\hline Employment & 191 & 38.2 \\
\hline Pocket money & 148 & 29.6 \\
\hline Borrowed & 129 & 25.8 \\
\hline Stolen & 32 & 6.4 \\
\hline
\end{tabular}

\section{Beliefs about the causes of drug use}

A majority of respondents started drug use due to bad social influences (keeping "bad company") (47.0\%). The second main cause was poor employment opportunities and financial difficulties (23.4\%). Some users developed their habit after using prescribed drugs (6.6\%), while a few attributed it to ease of availability of drugs (3.2\%) (Table 4)

On a psychological level, the most common reason given by respondents for starting drug use was stressful life events (28.0\%), poor marital relations (21.4\%), feeling of failure in life (18.2\%) and poor parental relations (15.8\%) (Table 4). Only 25.4\% blamed themselves for starting drug use; the rest put the blame on their socioeconomic situation, parents/friends or a psychological or emotional crisis

\section{Attitudes to quitting}

A high proportion (78.2\%) of drug users wanted to quit their drug habit, while $21.8 \%$ were not willing to quit. Less than a third of the respondents (29.0\%) had ever tried to give up drug use by themselves and the rest had never attempted to quit $(38.8 \%)$ or thought that they could not do so (32.2\%).

When asked about the conditions in which they would be ready to quit drug use, $37.8 \%$ of respondents agreed they would quit if their employment/financial problems were solved or if their family life became more stable (29.4\%) or they achieved success in life (10.6\%); $21.8 \%$ did not recognize the need to give up their addiction.

\section{Beliefs about effect of drug use on social life}

A majority of the respondents reported that their parents/family (54.8\%) knew about their involvement in drug use; $15.6 \%$ of users satisfied their needs at home, $44.6 \%$ took drugs on the street and the remainder (44.6\%) used drugs at friends' homes. When asked about 


\begin{tabular}{|c|c|c|}
\hline Variable & $\begin{array}{l}\text { No. of } \\
\text { respondents }\end{array}$ & $\%$ \\
\hline \multicolumn{3}{|l|}{ Mood before taking drugs } \\
\hline Addiction urge/dizziness/body aches & 121 & 24.2 \\
\hline Anxiety/anger & 117 & 23.4 \\
\hline Loss of sleep/restlessness & 93 & 18.6 \\
\hline Vertigo/headaches & 89 & 17.8 \\
\hline Depression/feeling sad & 80 & 16.0 \\
\hline \multicolumn{3}{|l|}{ Mood after taking drugs } \\
\hline Relaxed, calm and peaceful & 110 & 22.0 \\
\hline Feeling that all problems are solved & 97 & 19.4 \\
\hline Physically active & 87 & 17.4 \\
\hline Healthy and refreshing & 73 & 14.6 \\
\hline Psychologically strong & 69 & 13.8 \\
\hline Mood elevation & 64 & 12.8 \\
\hline
\end{tabular}

others' response to their drug use, $42.6 \%$ believed that their parents or family

wanted them to stop, but $30.4 \%$ thought that they did not care. Over half of drug

\begin{tabular}{|c|c|c|}
\hline Variable & $\begin{array}{l}\text { No. of } \\
\text { respondents }\end{array}$ & $\%$ \\
\hline \multicolumn{3}{|l|}{ Beliefs about origins of their drug use } \\
\hline Keeping "bad company" & 235 & 47.0 \\
\hline Employment/financial problems & 55 & 23.4 \\
\hline No reason (by chance) & 44 & 8.8 \\
\hline After using prescribed drugs & 33 & 6.6 \\
\hline Ease of availability & 16 & 3.2 \\
\hline Other & 55 & 11.0 \\
\hline \multicolumn{3}{|c|}{$\begin{array}{l}\text { Beliefs about psychological factors leading } \\
\text { to their drug use }\end{array}$} \\
\hline Stressful life events & 140 & 28.0 \\
\hline Poor marital relations & 107 & 21.4 \\
\hline Feeling of failure in life & 91 & 18.2 \\
\hline Poor parental relations & 79 & 15.8 \\
\hline Chronic illness & 44 & 8.8 \\
\hline Relationship breakup & 39 & 7.8 \\
\hline \multicolumn{3}{|c|}{$\begin{array}{l}\text { Beliefs about who/what to blame for start of } \\
\text { their drug use }\end{array}$} \\
\hline Employment/financial crisis & 186 & 37.2 \\
\hline Myself & 127 & 25.4 \\
\hline Parents/friends/relatives & 113 & 22.6 \\
\hline Psychological or emotional crisis & 74 & 14.8 \\
\hline \multicolumn{3}{|c|}{$\begin{array}{l}\text { Beliefs about parental/family response to their } \\
\text { drug use }\end{array}$} \\
\hline They want me to get stop it & 213 & 42.6 \\
\hline They can't help me & 135 & 27.0 \\
\hline They don't care & 152 & 30.4 \\
\hline
\end{tabular}

users $(56.8 \%)$ admitted that their relationships with their family or friends were affected by their habit, whereas $43.2 \%$ believed there was no effect on relationships. Of the respondents, $41.2 \%$ perceived themselves as active and contributing members of society and $58.2 \%$ believed that they were not a source of harm to society.

\section{Discussion}

The present study of drug users in Karachi assessed the demographic data and patterns of type of drug use. Drug users tended to be younger: individuals aged between 15 and 20 years made up 50\% of this sample of drug users. Women were only $22.2 \%$ of the sample. The most frequent mode of administration of drugs was through nasal inhalation (31.6\%) or smoking (28.0\%). However, $8.0 \%$ used parenteral routes or a combination of oral and parenteral routes (12.8\%). Injecting drug use is associated with the spread of bloodborne infections. Most of the drug users (67.8\% in total) paid from their salary or pocket money to buy drugs. Some of them borrowed money from friends and a few admitted to stealing money to fund their drug use.

The study also assessment drug users' beliefs about the causes of their drug use and the effect it had on family and friends. A high proportion of drug users (45.0\% in total) reported relationship problems as the main psychological factor leading to their drug use: poor relations with parents or a spouse or break-up of a relationship. Most drug users said that they took drugs as an escape from stressful life events (28.0\%) or feelings of failure (18.2\%). They reported feelings of calm and peacefulness (22.0\%), that all their problems were solved (19.4\%) and general mood elevation (12.8\%) after taking drugs. Previous surveys distinguished the factors that teenagers susceptible to drug abuse can often be identified by risk factors, 
such as emotional problems, depression or anxiety. These in turn create low selfesteem and a desire to escape feelings such as self-doubt, powerlessness and hopelessness leading to poor coping skills. This is why the use of psychoactive drugs is quite common in society even among those without any psychiatric disease [11-15].

Almost half of the drug users blamed their drug use on bad social influences (47.0\%) or socioeconomic problems (23.4\%), while a few (3.2\%) commented on the easy access to socially acceptable drugs such as alcohol, caffeine, central nervous system depressants, mood elevators, etc. A few individuals (6.6\%) developed drug addiction after using prescribed drugs such as opiates, benzodiazepines and barbiturates for short-term treatment. Many respondents expressed a wish to quit their drug use habit, but $38.8 \%$ had never tried to quit, while $32.0 \%$ believed that they were unable to give up the addiction. They believed that drug use was the best solution to their problems, giving them feelings of euphoria, heightened pleasure and reduced anxiety and depression. While more than half of drug users (56.8\%) admitted that their habit had affected their relationships with family and friends, 58.8\% believed that they were contributing towards society and their habit were harmless. On exploring the willingness of drug users to quit, many of them said they would quit if their employment/financial problems were solved or they could enjoy a settled family life.

The ease of availability of narcotic drugs and psychotropic substances in many areas of Karachi has become a public health concern. The government of Pakistan has instituted a series of measures to address the situation but has not completed the implementation of these. A comprehensive drug abuse control strategy demands a realistic assessment of the scope of the problem [16]. The available data indicate a significant increase in the use of morphine, heroin, opium, codeine, barbiturates and other natural, synthetic and semisynthetics drugs in Karachi [16].

Our study confirms that habitual use of drugs to alter one's mood, emotions and state of consciousness is very common in our society. Psychological and socioeconomic factors that lead people to abuse drugs should be addressed at the government level in order to limit the risk of addiction in society. Education and awareness programmes for the public may help to prevent the inappropriate use of psychoactive drugs and opiates. Regular interventions to control the use of these drugs are also recommended.

\section{References}

1. Bennett PN, Brown MJ, eds. Clinical pharmacology, 9th ed. Edinburgh, Churchill Livingstone, 2003.

2. Wallace JM Jr, Bachman JG. Explaining racial/ethnic differences in drug use: the impact of background and lifestyle. Social Problems, 1991, 38:333-357.

3. Newcomb MD et al. Substance abuse and psychosocial risk factors among teenagers: associations with sex, age, ethnicity, and type of school. American Journal of Drug and Alcohol Abuse, 1987, 13:413-433.

4. Koob G, Kreek MJ. Stress, dysregulation of drug reward pathways, and the transition to drug dependence. American Journal of Psychiatry, 2007, 164:1149-1159.

5. Kalivas PW, Volkow ND. The neural basis of addiction: a pathology of motivation and choice. American Journal of Psychiatry, 2005, 162:1403-1413.

6. Spanagel R, Weiss F. The dopamine hypothesis of reward: past and current status. Trends in Neurosciences, 1999, 22:521-527.

7. Stolerman I. Drugs of abuse: behavioural principles, methods and terms. Trends in Pharmacological Sciences, 1992, 13:170-176.

8. O'Brien CP. Drug addiction and drug abuse. In: Brunton LL, Lazo JS, Parker KL, eds. Goodman and Gilman's the pharmacological basis of therapeutics, 11th ed. New York, McGraw-Hill, 2006.
9. Scott J. Substance use and misuse. In: Winfield AJ, Richards RME, eds. Pharmaceutical practice, 3rd ed. Edinburgh, Churchill Livingstone, 2007.

10. Niaz $\cup$ et al. A survey of psychosocial correlates of drug abuse in young adults aged 16-21, in Karachi; identifying "high risk" population to target interventions strategies. Pakistan Journal of Medical Sciences, 2005, 21:271-277.

11. Harvey RA et al., eds. Lippincott's illustrated reviews: pharmacology. Philadelphia, Lippincott William and Wilkins, 2006.

12. Byrne B. Relationships between anxiety, fear, self-esteem, and coping strategies in adolescence. Adolescence, 2000, 35:201-215.

13. Tripathi KD. Essentials of medical pharmacology. New Delhi, Jaypee Brothers Medical Publishers, 2003.

14. Wexler M. Adolescent drug use and psychological health: a longitudinal study. American Psychologist, 1991, 46:165.

15. Luscher C. Drugs of abuse. In: Katzung BG, ed. Basic and clinical pharmacology, 10th ed. New York, McGraw-Hill, 2007.

16. Drug abuse assessment study of Pakistan 2000-01. Islamabad, Pakistan, Anti Narcotics Force in association with United Nations Drug Control Programme, 2001. 